\title{
APLICAÇÕES DE HIDROGÉIS COMO BIOMATERIAIS: UMA REVISÃO DE DISSERTAÇÕES E TESES BRASILEIRAS DESDE $2017^{1}$
}

\author{
APPLICATIONS OF HYDROGELS AS BIOMATERIALS: \\ A REVIEW OF BRAZILIAN DISSERTATIONS AND THESES SINCE 2017
}

\author{
Lucas Repecka Alves², Giovanni Miraveti Carriello ${ }^{3}$, \\ Guilherme Manassés Pegoraro ${ }^{4}$ e Jorge Fernandes Filho ${ }^{5}$
}

\section{RESUMO}

Os hidrogéis são um tipo de material reticulado que tem a capacidade de absorver grandes quantidades de água devido à presença em sua estrutura de grandes cadeias hidrofílicas. Estudos recentes indicam que, devido às suas características, podem ter diferentes aplicabilidades. Utilizando a Biblioteca Digital Brasileira de Teses e Dissertações com o intervalo de 2017 a 2021, foram selecionadas 73 dissertações e teses que, em suas pesquisas, investigaram o uso do hidrogel em algum tipo de aplicação como biomaterial. Os trabalhos revelaram que os hidrogéis têm sido pesquisados na área de engenharia de tecidos e na liberação de fármacos devido à biocompatibilidade que vários tipos de hidrogéis têm com o corpo humano.

Palavras-chave: Polímeros, tendências, pós-graduação.

\section{ABSTRACT}

Hydrogels are a type of crosslinked material that has the ability to absorb large amounts of water due to the presence in its structure of large hydrophilic chains. Recent studies indicate that, due to their characteristics, they may have different applicability. Using the Brazilian Digital Library of Theses and Dissertations with the interval from 2017 to 2021, 73 dissertations and theses were selected that, in their research, investigated the use of hydrogel in some type of application as a biomaterial. The works revealed that hydrogels have been researched in the area of tissue engineering and drug release due to the biocompatibility that various types of hydrogels have with the human body.

Keywords: Polymers, trends, graduate studies.

1 Trabalho de revisão bibliográfica.

2 Tecnólogo em Polímeros pela Faculdade de Tecnologia José Crespo Gonzales e Técnico em Química pela Escola Técnica Estadual Rubens de Faria e Souza. E-mail: lucasrepecka2@gmail.com

3 Aluno do curso de Licenciatura em Química da Universidade Federal de São Carlos e Técnico em Química pela Escola Técnica Estadual Rubens de Faria e Souza. E-mail:giovannimiraveti@gmail.com

4 Aluno do curso de Licenciatura em Química da Universidade Federal de São Carlos. E-mail: guilherme.ms.pegoraro@ gmail.com

5 Mestre em Ciências dos Materiais pela Universidade Federal de São Carlos. E-mail: jorgeferfilho@gmail.com 


\section{INTRODUÇÃO}

Uma das definições possíveis para hidrogéis é que são substâncias que entram em contato com sistemas biológicos. Eles podem ser encontrados em diversas formas, tal como em sólidos, líquidos, pastas e até mesmo géis, sendo que desta última categoria citada há os hidrogéis (PIRES, BIERHALZ; MORAES, 2015). Segundo Macêdo, Moura e Kramer (2020) os hidrogéis poliméricos podem ser definidos como um tipo de material que possui estruturas de redes hidrofílicas, as quais são reticuladas trimendisionalmente, fazendo-o com que o material possua a propriedade de absorver grandes quantidades de água com eficiência. Cassol, Fantinel e Silva (2020) define que a hidrofilicidade das cadeias poliméricas do hidrogéis e a densidade do agente reticulante são as principais condições que afetam a quantidade de água absorvida.

Macêdo, Moura e Kramer (2020) dizem que devido à diversidade de tipos de hidrogéis esse tipo de material vem se mostrando como uma opção para diversas aplicações como biomaterial, daí a importância de se realizar as pesquisas com hidrogéis. Como afirma Morosini (2009) a pós-graduação é um dos alicerces do Sistema Nacional de Ciência e Tecnologia, considerado para o autor uma das mais importantes bases para o desenvolvimento do Brasil, já que a maioria das pesquisas realizadas em solo nacional é oriunda das dissertações e teses dos programas de Mestrado e Doutorado no Brasil (STUEBER; TEIXEIRA, 2020).

Dessa forma, busca-se neste artigo analisar através do Biblioteca Digital Brasileira de Teses e Dissertações, com o recorte temporal de 2017 a 2021, as teses e dissertações sobre hidrogéis, analisando quais são as tendências da utilização do hidrogel como biomaterial em seres humanos, tendo como a definição biomaterial a de Pires, Bierlahz e Moral (2015).

\section{COLETA DE DADOS}

Utilizou-se para a realização dessa pesquisa a ferramenta de busca avançada da Biblioteca Digital Brasileira de Teses e Dissertações, selecionando-se o intervalo de ano da defesa 2017 a 2021. Buscou-se em todos os campos com o buscador booleano "hidrogel OR hidrogéis OR polímero OR polímeros". Analisou-se todas as dissertações e teses que retornaram, selecionando-se somente aquelas em que hidrogel era o material investigado no trabalho com uma aplicação de biomaterial, selecionando 73 dissertações e teses selecionadas. O levantamento foi realizado durante maio de 2021.

Posteriormente, analisou-se os trabalhos quanto à estrutura do hidrogel utilizado na pesquisa e sua aplicação, sendo que a partir do observado sobre os trabalhos foram criadas categorias para separar os materiais quanto à sua aplicação. 


\section{RESULTADOS E DISCUSSÃO}

Tabela 1 - trabalhos selecionados utilizando a Biblioteca Digital Brasileira de Teses e Dissertações selecionados referente ao ano de 2017.

\begin{tabular}{|c|c|c|}
\hline ESTRUTURA PRINCIPAL DO HIDROGEL & APLICAÇÃO DO HIDROGEL & REFERÊNCIA \\
\hline Laponita & Liberação de fármacos & Becher (2017) \\
\hline Quitosana metacrilamida + gelatina & Engenharia de tecidos & Carvalho (2017) \\
\hline Colágeno + hidroxiapatita + nanoqueratina & Engenharia de tecidos & Cavalcante (2017) \\
\hline Hidroxipropilmetilcelulose & Liberação de fármacos & Dias (2017) \\
\hline Quitosana & Liberação de fármacos & Galante (2017) \\
\hline Glucomanana & Tratamento de feridas & Genevro (2017) \\
\hline HydroMatrix Peptide Cell Culture Scaffold A6982 & Tratamento de feridas & Gomes (2017) \\
\hline Poli(álcool vinílico), quitosana e colágeno & Tratamento de feridas & Juvencio (2017) \\
\hline Alginato & Engenharia de tecidos & Leal (2017) \\
\hline Quitosana & Liberação de fármacos & Lorenzoni (2017) \\
\hline Carbopol, Natrosol e quitosana & Liberação de fármacos & Lucca (2017) \\
\hline Kappa carragenana + alfarroba & Tratamento de feridas & Marques (2017) \\
\hline Poli(ácido acrílico) e poli(metacrilato de metila) & Liberação de fármacos & Martins (2017) \\
\hline Poli(metacrilato de 2-hidroxietila) + polianilina & Engenharia de tecidos & Medeiros (2017) \\
\hline Quitosana + heteroramnana sulfatada & Engenharia de tecidos & Oikawa (2017) \\
\hline Creon & Liberação de fármacos & Olímpio (2017) \\
\hline Colágeno e gelatina & Liberação de fármacos & Oliveira (2017) \\
\hline Poli $(\gamma$-benzil-L-glutamato $)$ & Liberação de fármacos & Palácio (2017) \\
\hline Quitosana e Pluronic F-127 & Liberação de fármacos & Pelegrino (2017) \\
\hline Natrosol & Liberação de fármacos & Peterle (2017) \\
\hline Alginato + celulose & Engenharia de tecidos & Pieper (2017) \\
\hline Nanocelulose bacteriana + poli-L-lisina-colesterol & Tratamento de feridas & Pittela (2017) \\
\hline Alga Gigartina skottsbergii & Engenharia de tecidos & Rosa (2017) \\
\hline Alginato & Engenharia de tecidos & Santos (2017) \\
\hline Carragenana, pectina e pectina/carragenana & Liberação de fármacos & Silva (2017) \\
\hline Acrilamida e poliacrilato de amônia & Liberação de fármacos & Silveira (2017) \\
\hline Galactomanana & Liberação de fármacos & Sousa (2017) \\
\hline Galactomanana & Liberação de fármacos & Vasconcelos (2017) \\
\hline Álcool polivinílico + cisteína + agar + polietilenoglicol + papaína & Tratamento de feridas & Vicentine (2017) \\
\hline
\end{tabular}

Fonte: Construção do Autor.

Becher (2017) desenvolveu um hidrogel híbrido para aplicação como hidrogel injetável na liberação controlada de fármacos em locais específicos. O componente principal do hidrogel foi nanodiscos de laponita, além da água que constitui cerca de 95 a 97\% da estrutura do hidrogel. As formulações do hidrogel foram testadas em nanoescala utilizando o processo de nanoemulsão com os fármacos (cisplatina, fluorouracil e ciclofosfamida). Após a caracterização do material, os hidrogéis demonstraram ser biocompatíveis, biodegradáveis e robustos, o que os torna ideais para aplicação como hidrogéis injetáveis, além da sua eficiência anticâncer aos estarem retidos na estrutura dos nano-hidrogéis.

Carvalho (2017) utilizou a quitosana para o tratamento dérmico com a utilização de hidrogéis à base de quitosana metacrilamida e gelatina, a reticulação química da cadeia dos hidrogéis ocorreu 
por fotorreticulação sob radiação ultravioleta junto com fotoindicador 2-hidroxi-4'-(2-hidroxietoxi)2-metilpropiofenona e após finalizada a reação, o sistema foi estabilizado com o acréscimo de ácido ascórbico e após a caracterização o material demonstrou total biocompatibilidade e uma potencial aplicação para uso como curativo para feridas e reparação tecidual.

Cavalcante (2017) desenvolveu um hidrogel que simula a matriz extracelular, que apresentou hidrogéis reticulados com riboflavina/ultravioleta e biomateriais extraídos de peles, tendões, ossos e penas para reconstrução de tecido cartilaginoso, após isso os materiais foram caracterizados e purificados. Os hidrogéis obtidos de colágeno, hidroxiapatita e nanoqueratina apresentaram grande potencial de aplicabilidade no desenvolvimento de tecidos cartilaginosos.

Dias (2017) teve como objetivo a obtenção de uma fração enriquecida em isoflavonas de Trifolium pratense L. (trevo-vermelho) e avaliação da permeação cutânea das isoflavonas formononetina e biochanina A, devido à sua baixa hidrossolubilidade, são substâncias com grande limitação na aplicação em produtos para pele, com isso as mesmas foram incorporadas a hidrogéis de hidroxipropilmetilcelulose. As isoflavonas foram extraídas por maceração e precipitação por evaporação de etanol, com filtração e purificação por cromatografia. Os resultados de permeação cutânea demonstraram que as isoflavonas obtiveram um desempenho melhor quando aplicadas isoladamente, sendo que a biochanina A revelou a maior capacidade de permeação sobre a pele, destacando a sua capacidade de aplicação em preparações cosméticas para prevenção do envelhecimento cutâneo.

Galante (2017) estudou os efeitos da esterilização em propriedades de diferentes tipos de sistemas à base de hidrogel. Foram realizados métodos convencionais, como calor úmido e radiação gama, como também a esterilização por ozônio, um método novo, mas bastante promissor. Foi preparado um hidrogel natural nanoparticulado à base de quitosana (nanogel) e duas formulações de hidrogéis sintéticos para aplicações oftálmicas, com e sem fármacos. E os resultados obtidos apresentaram uma promissora aplicação para o método de esterilização por ozônio, tanto para o nanogel, quanto para os hidrogéis sintéticos sem a incorporação de fármacos (levofloxacina, diclofenac, timolol e clorhexidina), dado que os mesmos sofrem degradação quando expostos a um agente oxidante.

Genevro (2017) preparou membranas assimétricas para uso como curativos, as quais apresentam porosidade, facilitando a drenagem de fluídos da região lesionada, além de possuir uma película superior chamada camada densa, a qual regula a passagem dos micro-organismos e controla a perda excessiva de água, provendo os meios necessários para a recuperação do tecido lesionado. Devido à baixa resistência mecânica das membranas assimétricas por inversão de fases, foi preparada uma membrana assimétrica contendo apenas glucomanana de konjac, a qual apresentou maleabilidade, resistência mecânica, alta porcentagem de alongamento, taxa de transmissão de vapor de água e drenagem de fluídos, além de não ter demonstrado citotoxicidade, tratando-se de um promissor material para uso como curativo.

Gomes (2017) estudou a biocompatibilidade e atividade antimicrobiana de uma matriz hidrogel produzida pelo HydroMatrix Peptide Cell Culture Scaffold A6982, uma matriz comercial. 
Nessa matriz foi adicionado extrato de romã (Punica granatum L.) e obteve como resultado que o extrato de romã associado ou não à matriz de hidrogel obteve ausência de citotoxicidade, genototoxicidade e efeito antimicrobiano.

Juvencio (2017) realizou estudos na área de engenharia tecidual com a produção de filmes compostos de diferentes biomateriais para o tratamento de lesões de pele. Foi preparado filmes de álcool polivinílico, quitosana e colágeno e os caracterizou. Os resultados obtidos demonstram que o filme produzido apresenta promissoras aplicações como curativo cutâneo.

Leal (2017) sintetizou um hidrogel à base de alginato, oriundo de um copolímero derivado de um polissacarídeo de fonte natural, o qual apresentou biocompatibilidade, hidrofilia e baixo custo, podendo ser aplicado em diferentes áreas da saúde, como a liberação de drogas controlada. O autor sintetizou e caracterizou microesferas de hidrogel de alginato através da técnica de spray em solução de $\mathrm{CaCl}_{2}$ para crosslinking. Os resultados obtidos demonstraram que o material apresentou baixa citotoxicidadee s e mostrou um método simples e eficiente para obter microesferas de hidrogel de alginato, tratando-se de uma área com alta potencialidade para aplicação na odontologia, em especial na odontologia reparativa ou regenerativa.

Lorenzoni (2017) produziu e caracterizou hidrogéis de quitosana com capsaicinóides nanoencapsulados e comparou seu efeito terapêutico com hidrogéis de quitosana dissolvidos em solução etanólica, como também com creme comercial de referência para o tratamento da dor neuropática perfiférica com testes em camundongos. As suspensões de nanocápsulas foram obtidas através da técnica de deposição interfacil do polímero pré-formado. Os resultados obtidos demonstram que o nanoencapsulado mostra-se como uma potencial formulação a fim de se aperfeiçoar o tratamento da dor neuropática perfiférica quando comparado aos cremes de referência do mercado farmacêutico.

Lucca (2017) produziu nanoemulsões com óleo de copaíba, o qual possui como composto majoritário o $\beta$-cariofileno. Foram realizados estudos de avaliação de permeação cutânea, otimização da formulação e avaliação de atividade anti-inflamatória. Após realizados os testes, as nanoemulsões foram inseridas em hidrogéis de carbopol, natrosol e quitosana para uso tópico. Entre os três hidrogéis, apenas o natrosol foi escolhido como um promissor, uma vez que apresentou caráter neutro. Na avaliação da permeação cutânea das nanoemulsões contendo hidrogel, obteve-se um aumento na retenção de $\beta$-cariofileno na derme em relação às nanoemulsões, a atividade in vivo também demonstrou a capacidade anti-inflamatória do óleo, e sua incorporação em nanoemulsões intensificou este efeito.

Marques (2017) também desenvolveu curativos para o tratamento de feridas, porém com a utilização de nanopartículas de ouro em solução à base de hidrogéis de kappa carragenana e alfarroba para síntese de curativos hidrogel e wafer. As nanopartículas de ouro foram sintetizadas, simultaneamente em uma solução de kappa carragenana, alfarroba, glicerol e álcool polivinílico. E como resultado, essa solução apresentou poder redutor e estabilizante na síntese, formando com sucesso hidrogéis e wafers para aplicação de cicatrização de feridas cutâneas. 
Martins (2017) descreveu em seu trabalho a síntese de nanopartículas magnéticas de óxido de ferro encapsuladas em polímeros acrílicos com hidrogel. Foi utilizado o método de coprecipitação para a obtenção da magnetita $\left(\mathrm{Fe}_{3} \mathrm{O}_{4}\right)$ e encapsulada via polimerização por miniemulsão inversa para o poli(ácido acrílico) e direta para o poli(metacrilato de metila). Características como a baixa coercividade, comportamento superparamagnético e remanência das nanopartículas possibilitam aplicações médicas para a hipertemia. Dessa forma, o autor obteve partículas híbridas magnético-poliméricas estáveis em meio aquoso, as quais demonstram ser promissoras para o desenvolvimento de sistemas nanoestruturados, uma vez que são menos invasivas e mais eficientes. Não foi pesquisado nesse trabalho nenhum fármaco específico, mas devido às suas propriedades, o autor diz que o material possui potencialidades para aplicação no tratamento do câncer.

Medeiros (2017) desenvolveu um hidrogel eletroativo baseado no poli(metacrilato de 2-hidroxietila) e polianilina dopada com ácido canforsulfônico para utilização como interface biocompatível com uma superfície que imita o tecido cerebral, conferindo propriedades condutoras. O hidrogel foi obtido por eletrossíntese com voltametria cíclica e cronopotenciometria em uma solução de persulfato de amônio. O produto obtido apresentou facilidades de síntese, uma vez que pode ser obtido eletroquimicamente em atmosfera ar em temperatura ambiente, demonstrando ser um método eficaz, simples e de baixo custo, além de apresentar boa estabilidade química.

Oikawa (2017) preparou um biomaterial derivado de dois polissacarídeos, a heteroramnana sulfatada e a quitosana, com a finalidade de avaliação do cultivo de células-tronco mesenquimais. Os hidrogéis foram obtidos por complexação polietrólito dos polissacarídeos heteroramnana e quitosana examinada em diferentes proporções. Após isso, foi realizada uma avaliação do biomaterial in vitro com células-tronco mesenquimais isoladas do tecido adiposo humano, após caracterizadas, elas foram cultivadas nos hidrogéis por períodos de três, vinte e um e noventa dias, tendo como resultado agregados celulares. As análises demonstraram que as células-tronco foram adsorvidas pelo hidrogel com taxas de proliferação constantes, demonstrando ser uma promissora aplicação regenerativa como carreadores de células-tronco.

Olímpio (2017) sintetizou e caracterizou hidrogéis de biomateriais para agirem como veículos da pancreatina, a qual foi encapsulada em matrizes poliméricas, sendo a pancreatina um fármaco utilizado no tratamento de indivíduos que contêm deficiência ou insuficiência na produção de enzimas pancreáticas. Os estudos de liberação controlada foram realizados com os hidrogéis e liberação de uma formulação comercial, o Creon. Como resultado, todos os hidrogéis solubilizaram completamente na matriz polimérica, estimulando a liberação das enzimas no fluido intestinal, contudo o que se destacou foi o hidrogel de alginato, o qual apresentou maior eficiência de encapsulação e maior liberação de enzimas em pH próximo ao do local de aplicação.

Oliveira (2017) formulou e caracterizou hidrogéis de colágeno e gelatina reticulados com ácido cafeico para incorporação e liberação controlada de astaxantina. Tanto o colágeno, como a gelatina 
foram extraídos da pele da tilápia por solubilização ácida a $4{ }^{\circ} \mathrm{C}$ e extração em água a $60^{\circ} \mathrm{C}$, e ambos foram utilizados para formular o hidrogel para avaliar a influência do reticulante, ácido cafeico. Como resultado, o hidrogel de gelatina obteve a mais rápida liberação.

Palácio (2017) preparou, caracterizou e avaliou in vitro e in vivo nanopartículas específicas para o tratamento de melanoma e lipossomas com ß-lapachona inseridos em hidrógeis de biopolímero para cicratização de feridas tópicas. As nanopartículas foram obtidas por nanoprecipitação de copolímeros derivados do poli( $\gamma$-benzil-L-glutamato). Estudos hispatológicos acerca da atividade de cicatrização de feridas foram desenvolvidos em um modelo in vivo e o hidrogel demonstrou diversos pontos positivos, já que o mesmo estimulou o reparo tecidual, intensificando a celularidade local, fibroblastos, células inflamatórias e entre outros durante essa fase de crescimento, demonstrando um grande potencial para aplicações de cicatrização de feridas.

Pelegrino (2017) sintetizou e caracterizou nanopartículas à base de quitosana e hidrogéis aquosos de Pluronic F-127 contendo S-nitrosotióis. Os S-nitrosotióis podem ser utilizados como doadores de óxido nítrico, o que viabiliza seu uso terapêutico. As nanopartículas de quitosana foram preparadas por gelificação ionotrópica com o uso do íon tripolifosfato de sódio. Após isso, as nanopartículas foram inseridas sobre os hidrogéis aquosos, e os experimentos realizados demonstraram que a liberação de óxido nítrico permeia a pele humana, aumentando os estoques de óxido nítrico na epiderme e os ensaios de citotoxicidade não apresentaram toxicidade significativa para células saudáveis, tratando-se de um veículo benéfico para aplicações dermatológicas.

Peterle (2017) produziu um hidrogel com base no Natrosol contendo ß-cariofileno nanoemulsionado e avaliou os perfis de liberação/permeação cutânea in vitro e sua atividade cicatrizante in vivo. Foi também preparada uma nanoemulsão com homogeneizador de alta pressão, a qual foi dispersada diretamente com natrosol. Após as caracterizações, os resultados apontaram que durante a atividade cicatrizante, o fechamento da ferida foi alcançado em um menor tempo no grupo contendo hidrogéis com ß-cariofileno nanoemulsionado, o que demonstra seu efeito anti-inflamatório. A análise histológica também indicou que o hidrogéis com $ß$-cariofileno nanoemulsionado obtiveram resultados semelhantes ao grupo controle, tratando-se um composto eficaz para reparação cutânea.

Pieper (2017) produziu uma membrana de hidrogel de alginato com celulose, hidroxiapatita, óxido de grafeno e chalconas com características antimicrobianas. A obtenção da celulose foi através de resíduos agroindustriais, como o talo da casca de banana, e então a celulose foi recoberta com hidroxiapatita. Para a elaboração das membranas, foi adicionado ao alginato hidroxiapatita, celulose precipitada, hidroxiapatita com óxido de grafeno e chalconas, após a homogeinização, os materiais foram congelados e liofilizados. Os resultados mostraram-se positivos com a união das propriedades dos diferentes materiais, demonstrando ótima biocompatibilidade na aplicação de cicatrização e regeneração tecidual.

Pittela (2017) explorou a utilização da nanocelulose bacteriana como material de suporte para o crescimento celular (scaffold) com uma inédita modificação em sua superfície com o auxílio da 
adsorção do polímero poli-L-lisina-colesterol de modo a aprimorar a adesão e proliferação celular desse biomaterial, com isso foi desenvolvido uma nanocelulose bacteriana incorporada com Aloe vera. A aplicação dos compósitos de nanocelulose bacteriana com Aloe vera sobre a pele em seres humanos demonstrou bons resultados, haja visto que não foi observado nenhum sintoma ou sinal de alergia pelos voluntários, constatando, assim ser um biomaterial seguro para aplicações em humanos.

Rosa (2017) desenvolveu e caracterizou em sua pesquisa um novo tipo de scaffold injetável derivado da alga rodofícea Gigartina skottsbergii, a qual foi sintetizada e processada em hidrogel. Após isso, foi analisada a viabilidade e capacidade de adesão celular através do ensaio colorimétrico de WST-1 e da microscopia eletrônica de varredura (MEV). Os resultados obtidos demonstraram que as células encontraram-se em grande quantidade e área para a adesão celular, com uma morfologia aloganda possuindo prolongamentos.

Santos (2017) cultivou e avaliou a viabilidade de células tronco mensenquimais encapsuladas em um arcabouço tridimensional composto por hidrogel de alginato, como também avaliou a migração celular com o uso de nanocristal Qtracker 655. Para tanto, foram coletados fragmentos de uma membrana sinoval da articulação metatarsofalangeana de equinos, submetidos à digestão enzimática e então, cultivados em monocamadas. Posteriormente, as células foram encapsuladas em solução de alginato de sódio, e em seguida gelatinadas, formando o hidrogel de alginato e cultivadas por 4 semanas. Os resultados apresentaram a eficiência do hidrogel de alginato utilizado como scaffold, proporcionando viabilidade e estimulando a diferenciação condrogênica.

Silva (2017), preparou e caracterizou hidrogel de carragenana, pectina e pectina/carragenana encapsulado a $\beta$-galactosidase. As pérolas de hidrogel foram obtidas pela injeção de uma solução polimérica contendo a enzima na presença de uma solução salina. O teste de liberação controlada dos hidrogéis de carragenana e pectina foram 2,0 e 2,4 vezes superiores ao comprimido comercial na avaliação de liberação in vitro da $\beta$-galactosidase.

Silveira (2017) desenvolveu compostos à base de cimento ósseo de fosfato tricálcico e fosfato tricálcico de dupla pega, este que possui acrilamida em sua composição, agregados aos fármacos sulfato de gentamicina, cloridratos de lidocaína, bupivacaína e levobupivacaína a fim de testar sua liberação de fármacos. Primeiramente, testes foram produzidos com corpos de prova à base de cimento de fosfato tricálcico e fosfato tricálcico de dupla, com e sem adição de fármacos. Após isso, os materiais foram caracterizados e posteriormente foi estudado a cinética da liberação dos fármacos in vitro. Os resultados apontaram que ambos os cimentos funcionaram como sistemas de liberação dos fármacos, destacando o sistema com hidrogel, que obteve a maior resistência mecânica.

Sousa (2017) desenvolveu um trabalho com as lectinas vegetais, que são capazes de se ligar à superfície celular sem alterar as ligações covalentes presentes. Segundo o autor, essa propriedade é 
interessante porque permite uma efetiva atividade anti-inflamatória e imunoestimulante. A sua pesquisa foi focada nas lectinas jacalina, frutalina, lectina das sementes de Dioclea altissima e lectina presente nas sementes de amendoim (Arachis hypogea), entretanto apenas a frutalina respondeu aos ensaios positivamente em consórcio com hidrogéis de matriz de galactomanana como biomolécula capaz de ser explorada em formulações para tratamento de lesões na pele.

Vasconcelos (2017) também explorou o processo cicatricial, mas com modelos experimentais de ferida a fim de avaliar o efeito da fração protéica de Calotropis procera. Com o desenvolvimento de um hidrogel contendo galactomanana, como veículo de liberação de proteínas imunomoduladoras utilizando Caesalpinea pulchemirra, como excipiente e proteínas laticíferas. Os ensaios realizados em camundongos demonstraram resultados satisfatórios e o hidrogel à base de proteínas laticíferas não apresentou irritação dérmica e estimulou a cicatrização de feridas de forma eficiente.

Vicentine (2017) utilizou membranas de hidrogel, compostas por álcool polivinílico, cisteína, ágar, polietilenoglicol, papaína e água para o tratamento de úlceras em pés diabéticos. Para isso, 18 pacientes participaram do estudo e apenas 7 foram tratados com a membrana de hidrogel com papaína. Os resultados obtidos com a membrana apontaram baixa taxa de absorção do exsudato, como também alta rigidez, os quais contribuiram para o retardo do processo de cicatrização, que acabou não aderindo à pele e à ferida e não apresentando melhora significativa às feridas do pé diabético.

Tabela 2 - trabalhos selecionados utilizando a Biblioteca Digital Brasileira de Teses e Dissertações selecionados referente ao ano de 2018.

\begin{tabular}{|c|c|c|}
\hline ESTRUTURA PRINCIPAL DO HIDROGEL & $\begin{array}{c}\text { APLICAÇÃO DO } \\
\text { HIDROGEL }\end{array}$ & REFERÊNCIA \\
\hline Colágeno hidrolisado + goma gelana + amido & Liberação de fármacos & Almeida (2018) \\
\hline Quitosana & Liberação de fármacos & Andrade (2018) \\
\hline Poliacrilamida & Liberação de fármacos & Bortolin (2018) \\
\hline Poliacrilamida & Liberação de fármacos & Bortolon (2018) \\
\hline Quitosana + polietilenoglicol & Engenharia de tecidos & Bronzel (2018) \\
\hline Poli-(N-isopropilacrilamida-co-ácido acrílico) & Liberação de fármacos & Cabrini (2018) \\
\hline Poli (N-isopropilacrilamida) & Liberação de fármacos & Croisfelt (2018) \\
\hline Goma xantana & Liberação de fármacos & Ferreira (2018) \\
\hline Quitosana e poloxamer & Liberação de fármacos & Frade (2018) \\
\hline Metilparebelo + EDTA + hexametilcelulose + imidazolidinil ureia & Liberação de fármacos & Freitas (2018) \\
\hline Quitosana & Liberação de fármacos & Garcia (2018) \\
\hline Quitosana + álcool polivinílico & Liberação de fármacos & Guimarães (2018) \\
\hline Colágeno & Engenharia de tecidos & Lima (2018) \\
\hline Poli(N-2- vinil-pirolidona) + poli(etilenoglicol) + poli(etilenoglicol diacrilato $)$ & Liberação de fármacos & Maia (2018) \\
\hline $\begin{array}{l}\text { Poli }(\mathrm{N} \text {-isopropilacrilamida })+2 \text {-hidróxietil metacrilato + poli(L-co-D,L ácido } \\
\text { lático })+ \text { trimetileno carbonato e ácido acrílico }\end{array}$ & Engenharia de tecidos & Mistura (2018) \\
\hline Quitosana + gelatina & Engenharia de tecidos & Moreira (2018) \\
\hline Celulose bacteriana & Engenharia de tecidos & Moreno (2018) \\
\hline
\end{tabular}




\begin{tabular}{|c|c|c|}
\hline Carbômero & Liberação de fármacos & Morguete (2018) \\
\hline Carbopol Ultrez 10 & Liberação de fármacos & Muniz (2018) \\
\hline Colágeno & Liberação de fármacos & Oliveira (2018) \\
\hline Gelatina + dextrana & Liberação de fármacos & Piazza (2018) \\
\hline Polivinilpirrolidona & Liberação de fármacos & Rezende (2018) \\
\hline Álcool polivinílico + ácido hialurônico + titânico & Engenharia de tecidos & Ribeiro (2018) \\
\hline Pemulen $®$ TR2 & Liberação de fármacos & Rigon (2018) \\
\hline Eudragit & Liberação de fármacos & Rosa (2018) \\
\hline
\end{tabular}

Fonte: Construção do Autor.

Almeida (2018) desenvolveu um hidrogel para a liberação controlada de antocianina e colágeno hidrolisado em um hidrogel constituído com colágeno hidrolisado, gelana e amido. Foi notado comportamento em condições simuladas de $\mathrm{pH}$ similar ao do sistema gastrointestinal para uma potencial utilização em matriz alimentícia. Em seus resultados, ficou evidente as mudanças das propriedades do material e o autor aponta que é possível realizar modificações na estrutura para potencializar a entrega dos fármacos de acordo com as necessidades e propriedades do meio em que serão inseridos.

Andrade (2018) produziu nanopartículas de quitosana por meio da gelificação iônica, dissolvendo-a em ácido acético e mantendo o pH próximo de 5,2 com hidróxido de sódio, sob agitação. Foi adicionado N'-((5-nitrofurano-2-il)metileno)-benzidrazina, que tem propriedades antibacterianas, gotejando-o na solução de quitosana. Como agente reticulante, a autora usou tripolifosfato de sódio, além de usar glicerol para separação das partículas. O hidrogel combinado, que continha quitosana e o nitrocomposto foi o mais efetivo ante as bactérias testadas, sendo possível a aplicação do material no tratamento de queimaduras infeccionadas.

Bortolin (2018) estudou um hidrogel modificado com polissacarídeos e nanopartículas de óxido de ferro, sendo que em todas as composições de hidrogéis estudadas havia a presença da poliacrilamida, para que essa estrutura tivesse maior interação entre as nanopartículas e a matriz de hidrogel. A concentração de partículas magnéticas estudada variou de $0,5 \%$ a $2,0 \%$ e em todas as proporções, e o composto respondeu à variação do campo externo aplicado com mudança em suas propriedades de absorção de água e liberação de estreptomicina. Em seus testes, ele observou que a liberação da estreptomicina em uma cultura de Escherichia coli resultou em uma eficiência maior cerca de 5 vezes comparativamente com o bactericida sem a aplicação do campo magnético.

Bortolon (2018) em seu trabalho estudou a aplicação da fração flavonoídica purificada e micronizada em uma emulsão para aplicação tópica por meio de um hidrogel de poliacrilamida. Esses dois componentes são utilizados no tratamento da doença venosa crônica, com efeitos de redução do edema, redução da hiperpermeabilidade capilar e da migração de leucócitos nas paredes dos vasos. Os resultados obtidos apontam que tais sistemas podem ser usados para administração destes flavonoides venoativos na pele. 
Bronzel (2018) desenvolveu uma pesquisa na qual utilizou a quitosana e o polietilenoglicol como hidrogel e diferentes compostos químicos (silicato tricálcico, silicato dicálcico, fosfato de cálcio monobásico, hidróxido de cálcio, óxido de zircônio e tungstato de cálcio) na construção de um cimento para aplicação dentária. Seus resultados foram promissores e mais pesquisas na área devem ser conduzidas para uma possível substituição dos materiais que hoje são utilizados.

Cabrini (2018) em sua pesquisa com a utilização de hidrogel para uso em ferimentos, aplicou um carreador de óxido nítrico, o S-nitrosoglutationa, em uma matriz de poli-(N-isopropilacrilamida-co-ácido acrílico) com diferentes morfologias e diâmetros dos poros. As taxas de liberação do óxido nítrico ficou em uma taxa suficiente para promover ações anti-inflamatória e de cicatrização.

Croisfelt (2018) desenvolveu uma pesquisa da associação da bromelina na aplicação em um hidrogel de poli(N-isopropilacrilamida) objetivando a cicatrização e debridamento seletivo de queimaduras utilizando bromelina do abacaxi, extraída do abacaxi. A bromelina possui propriedades anti-inflamatórias e fibrinolítica. Os testes desenvolvidos apontaram que a liberação controlada do fármaco foi positiva e que apesar do estudo focar apenas nesta enzima, o estudo abre vértices para ouras aplicações deste tipo.

Ferreira (2018) dedicou seus estudos a desenvolver um hidrogel de goma xantana para a liberação de disseneleto de difenila para um tratamento ao combate da atividade tumoral do melanoma e do glioma, que segundo o autor são de elevada agressividade. $\mathrm{O}$ autor ainda coloca que as terapias normalmente utilizadas para o tratamento do câncer possuem barreiras de toxicidade e baixa eficiência. A coleta dos resultados indica uma possível aplicabilidade deste tratamento, já que tanto incorporado no gel, quanto em solução aquosa, as cápsulas contendo o fármaco apresentaram potencial carreador nos sistemas biológicos.

Frade (2018) visando o tratamento de acne vulgar causada pela bactéria Cutibacterium acnes, desenvolveu um estudo sobre a eficácia do fotossensibilizador azul incorporado em hidrogel de quitosana e poloxamer no formato de um filme. Seus resultaram apontaram que o azul de metileno em solução teve menor redução da carga bacteriana do que quando incorporada no hidrogel.

Freitas (2018) também desenvolveu um trabalho acerca de um hidrogel composto de metilparebelo, EDTA, hexametilcelulose e imidazolidinil ureia, além de conter extrato de Hyptis pectinata para tratamento da úlcera venosa. Seus testes foram conduzidos in vivo e o hidrogel pareceu ser um candidato promissor para o tratamento de úlceras venosas com uma redução maior da enfermidade, comparativamente com o grupo controle. Ele sugere novos estudos para contribuir com esta descoberta.

Garcia (2018) desenvolveu um hidrogel à base de quitosana com óxido de zinco ou/e óleo essencial de Schinus terebenthifolius raddi (pimenta rosa). A sua ideia era criar uma alternativa terapêutica para o combate às bactérias resistentes, visto que esta é uma preocupação presente nos sistemas de saúde. A quitosana é difundida por suas propriedades biocompatíveis e o óleo essencial da pimenta rosa, possui atividade bactericida contribuindo para a finalidade do estudo. Nas bactérias estudadas, 
todas apresentaram sensibilidade à formulação, no entanto a fórmula apresentou-se citotóxica em concentrações acima de 0,01 até $1 \mathrm{mg} / \mathrm{mL}$.

Guimarães (2018) pesquisou a aplicabilidade de hidrogéis de quitosana e álcool polivinílico (em diferentes proporções entre si), com ofármaco ibuprofeno, na obtenção de uma matriz dérmica como carreador do medicamento. No ensaio de liberação, ficou evidente que o maior teor de álcool polivinílico exerceu melhor liberação o ibuprofeno, indicando que este material pode ser usado como curativos em tratamentos em que o tecido foi lesionado.

Lima (2018) desenvolveu e caracterizou um hidrogel partindo de uma matriz de colágeno de peixe com apatitas de cálcio e estrôncio para o desenvolvimento de scaffolds reticulados com curcumina (princípio ativo do cúrcuma). Os hidrogéis apresentam resultados compatíveis com o esperado na formação de arcabouços e o uso do agente reticulante inovador, traz vantagens na sua utilização, já que o mesmo é biocompatível e bioativo podendo ser liberado no meio fisiológico.

Maia (2018) em seu trabalho utilizou a cafeína para realizar reticulação de um hidrogel e papaína, como objeto de estudo, para avaliar o seu comportamento na penetração. Os hidrogéis estudados eram compostos com poli(N-2- vinil-pirolidona), poli(etilenoglicol), poli(etilenoglicol diacrilato), para avaliar o comportamento cinético da papaína. Seus resultados in vitro foram satisfatórios em relação à eficácia da papaína como substância para a aplicação tópica. As características do produto, conforme o autor, podem ser estudadas para a aplicação de fármacos, embora não tenha realizado, especificamente, testes com nenhum.

Mistura (2018) sintetizou um hidrogel a partir do poli(N-isopropilacrilamida), poli(L-co-D,L ácido lático), 2-hidróxietil metacrilato, trimetileno carbonato e ácido acrílico, com o objetivo de criar um material que fosse biodegradável para uso em engenharia tecidual. Paralelamente, o autor buscou investigar como que o material criado pode servir como substratos para células tronco embrionárias do tipo cardiomiócitos no processo de diferenciação celular, visando uma aplicação na regeneração do tecido cardíaco. A análise dos seus resultados indica que pelo fato de haver uma reorganização tecidual feita pela compartimentalização do hidrogel, isto já é um indicativo de que a aplicação do material como substituto do tecido original pode ser satisfatória.

Moreira (2018) estudou os efeitos da incorporação de um hidrogel injetável composto de quitosana e gelatina associados a nanopartículas de vidro bioativo para uma possível utilização de regeneração óssea. O autor caracterizou este material nos aspectos estruturais, composição química e do seu comportamento in vivo e in vitro. Durante as caracterizações, ficou evidente que o material não apresenta problemas em relação à sua citoxicidade nos ensaios in vivo e in vidro. Quando em comparação com regeneração óssea de controle, aqueles que foram objeto do estudo apresentaram uma taxa de regeneração óssea maior, o que aponta que o biomaterial é uma alternativa indicada para este tipo de aplicabilidade.

Moreno (2018) desenvolveu um hidrogel de celulose do melaço da cana-de-açúcar e avaliou a sua biocompatibilidade frente à recuperação do tecido cerebral após um traumatismo com testes 
in vitro e in vivo. $\mathrm{O}$ autor conclui que o material apresenta bons resultados e um resultado promissor para a neuroengenharia de tecidos como scaffolds para a regeneração desses tecidos.

Morguete (2018) desenvolveu um hidrogel à base de carbômero com óleo extraído da planta Copaifera officinalis (óleo de copaíba) que possui ação antimicrobiana. Em sua pesquisa, o autor não encontrou dano à estrutura da mucosa cervicovaginal, tampouco encontrou após tratamento com o hidrogel. Em relação à atividade antimicrobiana, os resultados foram satisfatórios colocando que a formulação possui alto potencial para ser utilizado na prevenção da transmissão das bactérias aos recém-nascidos.

Muniz (2018) aplicou os anestésicos locais lidocaína e prilocaína com o objetivo de avaliar o comportamento dos hidrogéis à base de Carbopol Ultrez 10 (hidrogel comercial) contendo-os em nanocápsulas de poli(epsilon-caprolactona) ou não para uso tópico na mucosa oral. A formulação semissólida para liberação dos anestésicos locais para uso em mucosa oral apresentou boa propriedade mecânica, estabilidade e mucoadesivo eficiente. Estudos subjacentes devem ser realizados para que testes sejam feitos em humanos, abrindo possibilidades para uma melhoria na qualidade da anestesia tópica.

Oliveira (2018) extraiu colágeno de peixes e elaborou um hidrogel contendo glicosaminoglicano que é utilizado no tratamento de osteoartrose e microcápsulas contendo carotenóides. Observando os resultados das análises, os hidrogéis podem ser utilizados como encapsuladores de carotenóides para aplicações com alto valor agregado, com diferentes agentes reticulantes e ainda possuem propriedades que permitem que sejam utilizadas para liberação de fármacos.

Piazza (2018) desenvolveu uma plataforma de liberação de diclofenaco de potássio e metrotrexato. O hidrogel utilizado, composto de gelatina e dextrana, foi reticulado a partir das reações de click, nos quais as estruturas poliméricas foram modificadas com anidrido maleico e ácido furóico. $\mathrm{O}$ autor estudou a liberação do fármaco em diferentes meios e observou que quanto maior o intumescimento, mais rápida é a liberação do diclofenaco e quanto maior foi o tamanho da cadeia, maior é a liberação do metrotrexato.

Rezende (2018) também desenvolveu um hidrogel de polivinilpiorrolidona para liberação de fármaco para uso tópico no tratamento de feridas. O autor utilizou nanopartículas de óxido de cério (IV), junto com a Calendula officinalis e a Bixa orellana L. que são ativos utilizados para a ação bacteriana, antinflamatória, bem como antioxidante. Seu material resultou em um filme de hidrogel com o objetivo de avaliar a eficiência na cicatrização. Os resultados dos testes in vivo mostraram uma eficiência maior com a Calendula officinalis na diminuição do tamanho do ferimento.

Ribeiro (2018) aponta que a artrose é a terceira doença de maior incidência no mundo. Como alternativa ao tratamento desta enfermidade, o autor avaliou a aplicação das células tronco mesenquimais da polpa de leite humano em associação com o biomaterial formado por álcool polivinílico, ácido hialurônico e titânio metálico na forma de pó, que foi chamado pelo autor de trigel. O ensaio consistiu, em síntese, na aplicação deste compósito diretamente na lesão de ratos, o que se mostrou 
efetivo em parte para a regeneração do tecido desses animais. Ao final do ensaio ficou evidenciada a necessidade de outros testes e um número maior de experimentos que possam avaliar a capacidade regenerativa e os efeitos de toxicidade e biocompatibilidade do material ensaiado.

Rigon (2018) avaliou a utilização do silibinina no tratamento de dermatite pela incorporação deste em nanocapsulas com óleo de romã. O hidrogel foi preparado com o polímero Pemulen® TR2 que é bioadesivo, permitindo que o material desenvolvido seja colado sobre a pele. O silibinina possui propriedade anti-inflamatória, e os resultados apresentados pelo autor indicam que a proposta desenvolvida é uma alternativa terapêutica visto que quando encapsulada, o fármaco apresentou resultados superiores ao grupo de controle, na qual o principio ativo não estava encapsulado.

Rosa (2018) também segue o caminho do desenvolvimento de hidrogéis aplicados em uso tópico. Seu estudo compreendeu a utilização desonida para tratamento de doenças dermatológicas. Para isso, o autor produziu suspensões de nanocápsulas poliméricas com o polímero Eudragit RL 100, utilizando o óleo de açaí ou triglicerídeos de cadeia média como núcleo oleoso e o desonida na concentração de $0,25 \mathrm{mg} / \mathrm{mL}$. Seus resultados obtidos apontam que os hidrogéis nanoestruturados apresentaram efeito similar ao da desonida disponível comercialmente.

Tabela 3 - trabalhos selecionados utilizando a Biblioteca Digital Brasileira de Teses e Dissertações selecionados referente ao ano de 2019.

\begin{tabular}{llc}
\hline \multicolumn{1}{c}{ ESTRUTURA PRINCIPAL DO HIDROGEL } & APLICAÇÃO DO & REFERÊNCIA \\
\hline Pectina + quitosana & Engenharia de tecidos & Almeida (2019) \\
\hline Fibroína & Engenharia de tecidos & Borba (2019) \\
\hline Eudragit RS100® & Liberação de fármacos & Dalcin (2019) \\
\hline Pemulen ${ }^{\circledR}$ TR1 & Liberação de fármacos & Gonçalves (2019) \\
\hline Alginato + celulose & Engenharia de tecidos & Junior (2019) \\
\hline Colágeno & Engenharia de tecidos & Longaray (2019) \\
\hline Pectina & Liberação de fármacos & Marques (2019) \\
\hline Ácido hialurônico + fibrina & Engenharia de tecidos & Melo (2019) \\
\hline Carboximetilcelulose & Engenharia de tecidos & Nissola (2019) \\
\hline Quitosana + polietilenoglicol & Engenharia de tecidos & Petry (2019) \\
\hline Poli(N-vinil-2-pirrolidona) + ácido acrílico & Liberação de fármacos & Pigatto (2019) \\
\hline Poloxamer & Liberação de fármacos & Pironi (2019) \\
\hline Gellan gum & Liberação de fármacos & Ribeiro (2019) \\
\hline Ácido hialurônico + resveratrol & Engenharia de tecidos & Sacomani (2019) \\
\hline Ácido hialurônico & Engenharia de tecidos & Silva (2019) \\
\hline
\end{tabular}

Fonte: Construção do Autor.

Almeida (2019) trabalhou com a produção de hidrogéis contendo nanopartículas de ouro. O autor as sintetizou em matriz de pectina e quitosana, por meio da diluição em solução aquosa de ácido clorídrico. De acordo com a autora, a proporção de 60:40 de pectina e quitosana produz um material estável, tanto na presença do precursor de ouro $\left(\mathrm{HAuCl}_{4}\right)$ quanto na sua ausência. As nanopartículas de ouro, 
quando introduzidas, tornaram o hidrogel mais rígido,apresentando também viabilidade celular, conforme testes realizados.

Borba (2019) apresentou um método de reticulação química para produção de hidrogéis de fibroína em metanol, variando sua concentração, rotacionando em vórtex e gelificando à temperatura ambiente. De acordo com o autor, o material teve um arranjo poroso tridimensional, possibilitando a introdução de células-tronco, fibroblastos e cardiomiócitos, permitindo a aplicação como matriz para retenção de células-tronco no tecido cardíaco.

Dalcin (2019) produziu nanocápsulas de hidrogel à base de Eudragit RS100® contendo dihidromiricetina, um flavonoide que apresenta atividade antioxidante. O material aparentou possuir uma capacidade fotoproteotra e também demonstra, a partir dos testes realizados, citotoxidade e genotoxicidade, o que é um potencial sinal que o material é seguro para uso tópico como fotoprotetor.

Gonçalves (2019) utilizou um hidrogel com base do hidrogel comercial Pemulen® TR1 contendo óleo de Melaleuca alternifolia Cheel com o intuito de avaliar a atividade antifúngica deste óleo frente a leveduras do gênero Candida spp. Para isso, o material foi encapsulado em nanocápsulas lipídicas. No final do trabalho o material sintetizado apresentou uma boa ação fungicida, antioxidante e estabilidade, mostrando-se um grande potencial desse material para a proposta inicial do trabalho.

Junior (2019) dissolveu alginato em água deionizada em agitador vórtex, seguida pela adição de celulose nanocristalina. Hidrogenofosfato de cálcio dihidratado foi usado para reticulação. Seguidamente, foi produzida uma tinta para impressão por extrusão. Segundo o autor, a celulose nanocristalina é capaz de aprimorar propriedades de viscosidade e comportamento sólido, além de identificar também que a concentração de cálcio na rota de síntese e o tempo de reticulação influenciam na produção de tintas para extrusão, tendo potencial para ser aplicado na obtenção de scaffold na engenharia de tecidos, conforme o autor.

Longaray (2019) estudou em seu trabalho um hidrogel de colágeno para a aplicação no tratamento de teciduais de joelhos em coelhos com lesões através da aplicação no material diretamente do tecido. O autor obteve dados que julgou satisfatórios e ainda ressaltou que os dados abrem possibilidade para investigações desse material em seres humanos.

Marques (2019) utilizou um hidrogel de pectina cítrica oxidada veicular a entrega in situ de nanocristais de flutamida, um fármaco antiandrógeno utilizado para o tratamento do câncer de próstata. Conforme o autor, os resultados foram promissores, uma vez que o material possui alto potencial para realizar os testes in vivo.

Melo (2019) produziu redes poliméricas semi-interpenetradas contendo ácido hialurônico, fibrina e plasma rico em leucócitos e plaquetas que, segundo a autora, podem ser aplicados na regeneração de tecidos. O hidrogel foi sintetizado por meio da mistura entre o plasma e o ácido hialurônico, homogeneização, e adição de soro contendo trombina e cloreto de cálcio. Houve viabilidade celular do material, além da menor rigidez do hidrogel em resposta à menor presença de ligações covalentes. 
De acordo com a autora, trata-se de um biomaterial promissor para regeneração de tecidos, já que permitiu a secreção celular de algumas citocinas.

Nissola (2019) sintetizou hidrogéis de carboximetilcelulose contendo lasiodiplodana, usando também metiparabeno, glicerina e água destilada na etapa de síntese. Conforme a autora, o uso tópico do hidrogel resultante foi efetivo em promover a cicatrização no organismo testado, haja vista o pH adequado, o potencial antioxidante e a estabilidade do material, estimulando também as fibras de colágeno.

Petry (2019) sintetizou diferentes hidrogéis a partir da solubilização de polietilenoglicol dimetacrilato em água deionizada ou em outra solução contendo quitosana em ácido acético, introduzindo também óxido de grafeno reduzido em diferentes proporções, em um terceiro caso. As reações foram iniciadas com bissulfito de sódio ou N,N,N',N'-tetrametiletilenodiamina, persulfato de potássio ou persulfato de amônio, mantendo a reação por meia hora. Uma proporção de $10 \%$ em polietilenoglicol dimetacrilato e $0,5 \%$ de quitosana e óxido de grafeno reduzido apresentou o melhor resultado em termos de propriedades mecânicas, sendo similar ao tecido muscular, mas testes de biocompatibilidade não foram realizados nesse trabalho.

Pigatto (2019) produziu hidrogéis de poli(N-vinil-2-pirrolidona) e poli(N-vinil-2-pirrolidona-ácido acrílico) em uma rota de polimerização com radicais livres, catalisado por N,N,N',N'tetrametiletilenodiamina e sob agitação por um dia. Subsequentemente, houve irradiação com luz ultravioleta e lavagem com água destilada. Os hidrogéis foram posteriormente dopados com heparina, com intuito de atuação como fármaco. Conforme a autora, a presença de ácido acrílico na estrutura do material proporcionou poros menores e menos inchamento, o que levou a uma liberação mais lenta do fármaco nos testes.

Pirone (2019) investigou como que um hidrogel à base de poloxomer pode servir para o controle do ácido ursólico para o tratamento de inflamações cutâneas, este em uma dispersão sólida. Este ácido, possui propriedades anti-inflamatórias e pode ser uma substância promissora para o tratamento de feridas. Ao final da pesquisa, o autor concluiu que o material apresenta biocompatibilidade e que pode ser utilizado para o tipo de tratamento proposto.

Ribeiro (2019) sintetizou hidrogéis a partir de pó de gellan gum, que foi dissolvido em água destilada à $90^{\circ} \mathrm{C}$, sendo então adicionadas suspensões de L. paracasei. A etapa de geleificação foi feita com cloreto de cálcio, seguida de liofilização por um dia. De acordo com o autor, o hidrogel produzido foi capaz de sustentar as células adicionadas, sendo compatível com elas, e o processo de liofilização garantiu uma viabilidade por períodos maiores do que uma semana. Foi possível determinar que o hidrogel mantém as propriedades antifúngicas da espécie, sendo viável a aplicação na prevenção da candidose bucal.

Sacomani (2019) desenvolveu um hidrogel com base de ácido hialurônico com resveratrol e avaliou a sua estabilidade com o tempol (uma substância antioxidante), tal como a possibilidade desse 
material visando a regeneração ortopédica. Ao final do trabalho o autor concluiu que o material apresentam boa biocompatibilidade e possuem potencial para serem utilizado na medicina regenerativa.

Silva (2019) produziu hidrogéis de ácido hialurônico, variando a proporção de 1,4-butanediol diglicidil éter como um agente reticulante na síntese. A rota usou agitação mecânica, homogeneização e intumescimento com água. Conforme a autora, os hidrogéis apresentaram alta hidrofilicidade, foram estáveis tanto quimicamente quanto mecanicamente e as proporções de $13 \%$ e $25 \%$ de 1,4-butanediol diglicidil foram adequadas para aplicação em enchimentos faciais. Outras proporções foram mais viáveis para viscosuplementação e géis fortes.

Tabela 4 - trabalhos selecionados utilizando a Biblioteca Digital Brasileira de Teses e Dissertações selecionados referente ao ano de 2020.

\begin{tabular}{lcc}
\hline \multicolumn{1}{c}{ ESTRUTURA PRINCIPAL DO HIDROGEL } & APLICAÇÃO DO HIDROGEL & REFERÊNCIA \\
\hline Alginato + biocerâmica + policaprolactona & Engenharia de tecidos & Brião (2020) \\
Metilcelulose + carboximetil quitosana + goma xantana & Liberação de fármacos & Westin (2020) \\
\hline \multicolumn{2}{c}{ Fonte Construção do Autor }
\end{tabular}

Fonte: Construção do Autor.

Brião (2020) desenvolvel scaffold a partir da combinação de um material mista de hidrogel de alginato, biocerâmica e policaprolactona, concluindo que o material conseguiu mimetizar o tecido ósseo, o que conforme a autora pode auxiliar a regeneração de ossos.

Westin (2020) desenvolveu 8 formações de hidrogéis utilizando três tipos de polissacarídeos (metilcelulose, goma xantana e carboximetil quitosana), os quais conforme o autor, possuem potencialidade para serem aplicados na engenharia de tecidos devido ao resultado dos testes realizados. O autor realizou testes sobre o controle de liberação de fármacos (ácido gálico, dexametasona e diclofenaco de sódio), onde concluiu que o hidrogel pode auxiliar na reconstrução do tecido cartilaginoso e a incorporação de fármacos em tecidos lesionados.

Tabela 5 - trabalhos selecionados utilizando a Biblioteca Digital Brasileira de Teses e Dissertações selecionados referente ao ano de 2021.

\begin{tabular}{lcc}
\hline \multicolumn{1}{c}{ ESTRUTURA PRINCIPAL DO HIDROGEL } & APLICAÇÃO DO HIDROGEL & REFERÊNCIA \\
\hline Pectina & Imiquimode & Gazzi (2021) \\
\hline Alginato de sódio & Produção de insulina & Morais (2021) \\
\hline \multicolumn{2}{c}{ Fonte: Construção do Autor. }
\end{tabular}

Gazzi (2021) desenvolveu um hidrogel a partir da pectina para atuar como um veículo semissólido para a liberação de imiquimode, um medicamento que é utilizado para o tratamento do melonoma, um tipo de câncer de pele. O imiquimode foi colocado em nanocápsulas poliméricas que eram dispersos no hidrogel, o que se demonstrou, nos ensaios de permeação in vitro, eficaz, visto que o imiquimode teve a sua permeação modulada pelo hidrogel, fazendo com que o fármaco conseguisse adentrar na derme. 
Morais (2021) desenvolveu um trabalho onde, utilizando diversas concentrações de alginato de sódio, desenvolveu um hidrogel para encapsular células min-6 em um sistema de produção e secreção de insulinas, sendo realizados diversos testes com outras matrizes juntamente com o alginato de sódio (agarose, amido, celulose, gelatina gelatina/polietilenoglicol, glicina e quitosana).

\section{CONCLUSÃo}

Na presente revisão executada constatou-se que as pesquisas de pós-graduação desde de 2017 brasileiras mostram uma potencial aplicabilidade dos materiais do tipo hidrogel para a engenharia de tecidos, onde diversos trabalhos ressaltaram a biocompatibilidade como uma das principais características do material significante para essa aplicação, como uma única exceção, a qual foi hipotetizada pelo próprio autor do trabalho a resíduos reagentes durante o processo e síntese do hidrogel. Interessante notar que dentro de aplicações relacionadas à engenharia de tecidos há uma gama grande de aplicações, tal como aplicação como scaffolds e como material implantável. Foi constatado também que os materiais do tipo hidrogéis podem ser utilizados no tratamento de feridas e também como uma matriz para a produção de enzimas, no caso a insulina. Sobre as pesquisas de liberação de fármacos, houve na presente revisão bastante trabalhos que investigaram aplicações tópicas dos hidrogéis, mas não se limitando tão somente a essas aplicações, mostrando que a tendência de pesquisas que envolvem a liberação controlada de fármacos veiculados a hidrogéis é em uso tópico, mas não se limitando exclusivamente a essa forma.

\section{REFERÊNCIAS}

ALMEIDA, D. A. Síntese in situ de nanopartículas de ouro para obtenção de compósitos com polissacarídeos visando aplicações biomédicas. 2019. 75 f. Dissertação (mestrado) - Universidade Tecnológica Federal do Paraná, Programa de Pós-Graduação em Ciências e Engenharia dos Materiais, Londrina, PR. 2019.

ALMEIDA, F. S. Desenvolvimento de partículas biopoliméricas recobertas para veicular compostos bioativos. 2018. 116f. Dissertação (mestrado) - Universidade Estadual de Campinas, Faculdade de Engenharia de Alimentos, Campinas, SP. 2018.

ANDRADE, L. F. Vetorização de compostos 5-nitro-heterocíclicos com atividade frente a microrganismos multirresistentes. Obtenção de nanopartículas carregadas e avaliação da atividade antimicrobiana. 2018. 114 f. Dissertação (mestrado) - Universidade de São Paulo, Pós-Graduação em Tecnologia Bioquímico-Farmacêutica, São Paulo, SP. 2018. 
BECHER, T. B. Síntese de novos hidrogéis injetáveis e nano-hidrogéis biodegradáveis para aplicações em vetorização em fármacos. 2017. 148 f. Tese (doutorado) - Universidade Estadual de Campinas, Instituto de Química, Campinas, 2017.

BORBA, P. B. Síntese, caracterização e avaliação da biocompatibilidade de um hidrogel de fibroína para a regeneração cardíaca. 2019. 75 f. Dissertação (mestrado) - Universidade Federal da Bahia; Instituto Gonçalo Moniz, Fundação Oswaldo Cruz, Salvador, 2019.

BORTOLIN, A. Hidrogéis magneto-reponsivos para liberação estimulada de fármacos. 2018. 92 f. Tese (doutorado) - Universidade Federal de São Carlos, Centro de Ciências Exatas e de Tecnologia, São Carlos, SP. 2018.

BORTOLON, F. F., Desenvolvimento de nanoemulsões contendo fração flavonoídica enriquecida com diosmina e hesperidina em hidrogeis para a aplicação tópica cutânea visando tratamento de doenças venosas crônicas. 2018. 159 f. Dissertação (mestrado) - Universidade Federal de Santa Catarina, Centro de Ciências da Saúde, Programa de Pós-Graduação em Farmácia, Florianópolis, 2018.

BRIÃO, M. M. M. Desenvolvimento de um substituto ósseo a partir da associação de biomateriais com células-tronco. 2020. 69 f. Dissertação (mestrado) - Universidade Federal do Rio Grande do Sul, Instituto de Ciências Básicas da Saúde, Porto Alegre, RS. 2020.

BRONZEL, C. L. Z. Desenvolvimento e avaliação de cimentos endodônticos à base de silicatos e cálcio. 2018 77f. Dissertação (mestrado) - Universidade Estadual Paulista “Júlio de Mesquita Filho", Faculdade de Odontologia de Araraquara. Araraquara, SP. 2018.

CABRINI, F. M. Hidrogéis de poli(N-isopropilacrilamida-co-ácido acrílico) modificados com Pluronic F127 para liberação tópica de óxido nítrico. 2018. 79 f. Dissertação (mestrado) - Universidade Estadual de Campinas, Instituto de Química, Campinas, SP. 2018.

CARVALHO, I. C. Hidrogéis híbridos poliméricos de quitosana funcionalizada e gelatina fotoreticulados como matrizes porosas tridimensionais para potencial reparo de tecido epitelial. 2017, 151 f. Dissertação (mestrado), Universidade Federal de Minas Geais, Escolha de Engenharia, Belo Horizonte, MG. 2017. 
CASSOL, V.; FANTINEL, L.; SILVA, W. L. Estudo e viabilidade do revestimento de sementes da soja no processo da germinação a partir do uso de polímero hidrogel de amido de milho. Disciplinarum Scientia | Naturais e Tecnológicas, v. 21, n. 1, p. 103-115, 2020.

CAVALCANTE, F. L. Síntese de hidrogéis de colágeno, nanoqueratina e biopatita provenientes de sub-produtos da indústria avícola. 2017. 70 f. Dissertação (mestrado) - Universidade Federal do Ceará, Centro de Ciências, Fortaleza, CE. 2017.

CROISFELT, F. M. Hidrogéis de pnipaam-co-aam como sistemas carreadores de produtos bioativos de interesse farmacêutico. 2018. 76 f. Dissertação (mestrado) - Universidade Estadual de Campinas, Instituto de Biologia, Campinas, SP. 2018.

DALCIN, A. J. F. Avaliação da segurança e da capacidade fotoprotetora de hidrogéis contendo nanocápsulas catiônicas do flavonoide dihidromiricetina. 2019. 62f. Tese (doutorado), Universidade Franciscana, Programa de Pós-Graduação em Nanociências, Santa Maria, RS. 2019.

DIAS, P. H. Obtenção de fração enriquecida em isoflavonas de Trifolium pratense L e avaliação da permeação cutânea de formononetina e biochanina A incorporadas em hidrogel de HPMC contendo ciclodextrinas. 2017. 108 f. Dissertação (mestrado) - Universidade Federal do Rio Grande do Sul, Programa de Pós-Graduação em Ciências Farmacêuticas, Porto Alegre, RS. 2017.

FERREIRA, L. M. Sistemas de base nanotecnológica contendo disseleneto de difenila para o tratamento do melanoma e do glioma. 2018, 197f. Tese (doutorado) - Universidade Federal de Santa Maria, Centro de Ciências das Saúde. Santa Maria. RS. 2018

FRADE, M. L. Hidrogéis como sistema de liberação de fotossensibilizador para terapia fotodinâmica contra Cutibacterium (Propionibacterium) acnes. 2018. 102 f., Dissertação (mestrado), Universidade Estadual Paulista "Júlio de Mesquita Filho", Faculdade de Ciências Farmacêuticas, Araraquara, SP. 2018.

FREITAS, A. L. Avaliação da cicatrização de feridas por hidrogel contendo extrato seco padronizado de Hyptis pectinata (L.) em ratos. 2018.93 f. Tese (doutorado) - Universidade Federal de Sergipe, Pró-Reitoria de Pós-Graduação em Pesquisa, Aracaju, SE. 2018. 
GALANTE, R. S. C. Esterilização de hidrogéis para aplicações biomédicas. 2017. 233 f. Tese (doutorado) - Universidade de São Paulo, Programa de Pós-Graduação em Fármacos e Medicamentos, São Paulo, 2017.

GARCIA, S. M. S. Desenvolvimento e caracterização de hidrogel de quitosana aditivado com óxido de zinco e óleo essencial de Schinus terebenthifolius raddi (pimenta rosa). 2018. Tese (doutorado) - Universidade Federal de Pernambuco, Centro de Ciências Exatas e da Natureza, Recife, PE. 2018.

GAZZI, R. P. Desenvolvimento de hidrogel de pectina contendo nanocápsulas poliméricas de imiquimode visando ao tratamento do melanoma. 2021. 176. Dissertação (mestrado) - Universidade Federal do Rio Grande do Sul, Programa de Pós-Graduação em Ciência dos Materiais, Porto Alegre, 2021.

GENEVRO, G. M. Desenvolvimento de materiais microestruturados a partir de biopolímeros para obtenção de curativos de alto desempenho. 2017. 110 f. Tese (doutorado) - Universidade Estadual de Campinas, Faculdade de Engenharia Química, Campinas, 2017.

GOMES, L. A. P. Avaliação da biocompatibilidade e atividade antimicrobiana in vitro da matriz de hidrogel associada ao extrato glicólico de Punica granatum L. (Romã). 2017. 45 f. Dissertação (mestrado) - Universidade Estadual Paulista, Programa de Pós-Graduação em Biopatologia Bucal, SP. 2017.

GONÇALVES, H. R. M. Nanopartículas lipídicas sólidas contendo óleo essencial de Melaleuca alternifolia Cheel como plataforma inovadora no tratamento da candidíase orofaríngea. 2019, 115 f. Tese (doutorado) - Universidade Federal de Juiz de Fora, Faculdade de Medicina, Juiz de Fora, MG. 2019.

GUIMARÃES. A. A. S. Hidrogéis à base de quitosana/poli (álcool vinílico) para liberação de fármaco visando uso potencial como curativo. 2018. $180 \mathrm{f}$. Tese (doutorado). Universidade Federal da Paraíba, Programa de Pós-Graduação em Ciência e Engenharia de Materiais. João Pessoa, PB. 2018.

JUNIOR, E. A. Manufatura aditiva baseada em extrusão de hidrogéis do sistema alginato/ nanocelulose. 2019. 107f. Dissertação (mestrado) - Universidade Estadual de Campinas, Faculdade de Engenharia Mecânica, Campinas, SP. 2019.

JUVENCIO, L. R. F. Preparação e caracterização de filme de PVA/Quitosana/Colágeno visando a aplicação como curativo cutâneo. 2017. 69 f. Dissertação (mestrado) - Universidade Federal de São Carlos, Centro de Ciências e Tecnologias, Sorocaba, SP. 2017. 
LEAL, F. B. Hidrogel de alginato funcionalizado para utilização como sistema de entrega em Odontologia. 2017. 57 f. Tese (doutorado) - Universidade Federal de Pelotas. Programa de Pós-Graduação em Odontologia, Pelotas, RS. 2017.

LIMA, J. P. O. Arcabouços à base de colágeno de pele de Tilápia (Oreochromis niloticus) incorporados de apatitas para aplicações biomédicas. 2018. 69 f. Dissertação (mestrado em Química) Universidade Federal do Ceará, Fortaleza, 2018.

LONGARAY, M. P. Restauração da cartilagem hialina articular com uso de células-tronco mesenquimais, hidrogel de colágeno tipo II e condroblastos em lesão troclear do joelho. 2019, 85 f. Dissertação (mestrado) - Universidade Federal do Rio Grande do Sul, Instituto de Ciências Básicas da Saúde, Porto Alegre, RS. 2019.

LORENZONI, R. Hidrogel de quitosana contendo capsaicinóides nanoencapsulados: produção, caracterização, dermatofarmacocinética e avaliação farmacodinâmica em modelo animal de dor neuropática periférica. 2017. 177 f. Tese (doutorado) - Universidade Federal do Rio Grande do Sul, Faculdade de Farmácia, Porto Alegre, RS. 2017.

LUCCA, L. G. Nanoemulsões de óleo de copaíba (Copaifera multijuga Hayne): Desenvolvimento tecnológico, estudo de permeação cutânea e avaliação das atividades anti-inflamatória e leishmanicida tópicas. 2017. 223 f. Tese (doutorado) - Universidade Federal do Rio Grande do Sul, Programa de Pós-Graduação em Ciências Farmacêuticas, Porto Alegre, RS. 2017.

MACÊDO, A. R. S.; MOURA, A. M. M. A.; KRAMER, D. G. A importância dos hidrogéis na pesquisas antimicrobiana: revisão de literatura. Anuário Pesquisa e Extensão Unoesc São Miguel do Oeste, v. 5, p. e26554-e26554, 2020.

MAIA, T. C. S. Liberação e permeação dérmica "in vitro" de hidrogel de cafeína em comparação ao uso de papaína como promotora de permeação. 2018. 58f. Dissertação (mestrado) - Universidade de São Paulo, Instituto de Pesquisas Energéticas Nucleares. São Paulo, SP. 2018.

MARQUES, L. P. Nanocristais de flutamida para o tratamento de carcinoma prostático. 2019. 119 f.. Tese (doutorado) - Universidade Estadual de Campinas, Instituto de Química, Campinas, SP. 2019. 
MARQUES, M. S. Produção de curativos hidrogel e wafer à base de polissacarídeos contendo nanopartículas de ouro sintetizadas in situ. 2017. 124 f. Dissertação (mestrado) - Universidade do Sul de Santa Catarina, Programa de Pós-Graduação em Ciências da Saúde, Tubarão, SC. 2017.

MARTINS, M. G. Encapsulamento de nanopartículas magnéticas em polímeros acrílicos e avaliação de hipertermia para potencial tratamento de câncer. 2017. 135 f. Dissertação (mestrado) Universidade Estadual do Rio de Janeiro, Instituto Alberto Luiz Coimbra de Pós-Graduação e Pesquisa de Engenharia, Rio de Janeiro, RJ. 2017.

MEDEIROS, M. F. X. P. Desenvolvimento e caracterização de hidrogéis eletroativos baseados em poli(metacrilato de 2-hidroxietila) e poli(anilina). 2017. $188 \mathrm{f}$. Tese (doutorado) - Universidade Federal de Itajubá, Programa de Pós-Graduação em Materiais para Engenharia, Itajubá, MG. 2017.

MELO, B. Alice Gomes de. Padronização do L-PRP e formação de redes poliméricas semi-interpenetradas de ácido hialurônico e fibrina do L-PRP para diferenciação condrogênica e osteogênica de células mesenquimais de tecido adiposo humano. 2019. 198 f. Tese (doutorado) Universidade Estadual de Campinas, Faculdade de Engenharia Química, Campinas, SP. 2019.

MISTURA, D. V. Síntese e caracterização de uma classe de hidrogéis injetáveis, termossensíveis e biodegradáveis como substrato para diferenciação celular. 2018. 154 f. Tese (doutorado) Universidade Estadual de Campinas, Faculdade de Engenharia Mecânica, Campinas, SP. 2018.

MORAIS, E. C. Encapsulamento de células Min-6 como sistema de produção e secreção de insulina. 2020. 92. Tese (doutorado) - Universidade Federal do Rio Grande do Sul, Faculdade de Farmácia, Porto Alegre, 2021.

MOREIRA, C. D. F. Hidrogéis injetáveis a base de quitosana/gelatina/nanopartículas de vidro bioativo com potencial para regeneração óssea: estudo in vitro e in vivo. 2018. 153f. Tese (doutorado) Universidade Federal de Minas Gerais, Programa de Pós-Graduação em Engenharia Metalúrgica, Materiais e de Minas. Belo Horizonte, MG. 2018.

MORENO, G. M. M. Análise da biocompatibilidade do biopolímero da cana-de-açúcar em modelo de traumatismo craniano e em culturas de células neurais. 2018. $73 \mathrm{f}$. Tese (doutorado) Universidade Federal de Pernambuco, Centro de Biociências, Recife, PE. 2018. 
MORGUETE, A. E. B. Colonização por Streptococcus agalactiae em gestantes e formulação de hidrogel para controle de infecção neonatal. 2018. Dissertação (mestrado) - Universidade Estadual de Londrina. Centro de Ciências Biológicas, Programa de Pós-Graduação em Microbiologia, Londrina PR. 2018.

MOROSINI, M. C. A pós-graduação no Brasil: formação e desafios. Revista Argentina de Educación Superior, n. 1, p. 125-152, 2009.

MUNIZ, B. V. Hidrogel de lidocaína e prilocaína encapsulados em nanocápsulas de poli(épsilon-caprolactona) para anestesia tópica oral. 2018. 61 f. Tese (doutorado) - Universidade Estadual de Campinas, Faculdade de Odontologia de Piracicaba, Piracicaba, SP. 2018.

NISSOLA, C. Hidrogel contendo $(1 \rightarrow 6)-\beta$-D-glucana (lasiodiplodana): desenvolvimento, caracterização e avaliação da atividade cicatrizante. 2019. 83f. Dissertação (mestrado) - Universidade Tecnológica Federal do Paraná, Programa de Pós Graduação em Biotecnologia, Dois Vizinhos, PR. 2019.

OIKAWA, E. M. Desenvolvimento de biomaterial de quitosana e heteroramnana sulfatada estimulando células-tronco na produção de matriz extracelular. 2017. 210 f. Dissertação (mestrado) - Universidade Federal do Paraná, Programa de Pós-Graduação em Ciências (Bioquímica), Curitiba, PR. 2017.

OLÍMPIO, F. M. P. Preparação, caracterização e estudos de liberação controlada de pancreatina encapsulada em diferentes hidrogéis. 2017. 84 f. Dissertação (mestrado) - Universidade Federal de Alfenas, Alfenas, 2017.

OLIVEIRA, A. P. V. Hidrogéis de colágeno e sulfato de condroitina com diferentes agentes reticulante. 2018. 106 f. Dissertação (mestrado) - Universidade Federal do Ceará, Agrárias, Fortaleza, CE. 2018.

OLIVEIRA, J. M. Géis de colágeno e gelatina do resíduo da tilápia (Oreochromis niloticus) para incorporação e liberação controlada in vitro da astaxantina. 2017. 114 f. Dissertação (mestrado) - Universidade Federal do Ceará, Centro de Ciências Agrárias, Fortaleza, 2017.

PALÁCIO, S. B. Development and characterization of targeted mart-1-nanoparticles for melanoma treatment and $\beta$-lapachone-loaded liposomes in hydrogel for wound healing. 2017. 168 p. Tese (doutorado) - Universidade Federal de Pernambuco, Centro de Ciências da Saúde, Recife, 2017. 
PELEGRINO, M. T. Nanopartículas poliméricas doadoras de óxido nítrico para aplicações tópicas. 2017. 86 f. Dissertação (mestrado) - Universidade Federal de São Paulo, Instituto de Ciências Ambientais, Químicas e Farmacêuticas, Diadema, SP. 2017.

PETERLE, J. P. Estudo da atividade cicatrizante de hidrogel contendo B-cariofileno nanoemulsionado. 2017. 159 f. Dissertação (mestrado) - Universidade Federal do Rio Grande do Sul, Programa de Pós-Graduação em Ciências Farmacêuticas, Porto Alegre, 2017.

PETRY, J. F. T. C. Preparação de hidrogéis contendo quitosana-óxido de grafeno reduzido para potencial aplicação na engenharia de tecidos. 2019. 124 f. Dissertação (mestrado) - Universidade Federal do Rio Grande do Sul, Programa de Pós-Graduação em Química, Porto Alegre, RS. 2019.

PIAZZA, R. D. Click hidrogéis de gelatina e nanopartícula polimérica como plataforma de liberação simultânea de fármacos hidrofílico e hidrofóbico. 2018. 52 f. Tese (doutorado) - Universidade Estadual Paulista “Julio de Mesquita Filho”, Programa de Pós-Graduação em Química, Araraquara, SP. 2018.

PIEPER, C. M. Desenvolvimento de curativos flexíveis de alginato/celulose/hidroxiapatita sensíveis à presença de óxido de grafeno e chalconas. 2017. $107 \mathrm{f}$. Tese (doutorado) - Universidade Federal de Pelotas, Faculdade de Odontologia, Pelotas, RS. 2017.

PIGATTO, C. Recobrimento de stents metálicos com hidrogéis para liberação controlada de fármaco. 2019. 91f. Tese (doutorado) - Universidade Federal do Rio Grande do Sul, Programa de Pós-Graduação em Engenharia de Minas, Metalúrgica e de Materiais, Porto Alegre, RS. 2019.

PIRES, A. L. R.; BIERHALZ, A. C. K; MORAES, Â. M. Biomateriais: tipos, aplicações e mercado. Química Nova, v. 38, p. 957-971, 2015.

PIRONI, A. M. Dispersões sólidas de ácido ursólico veiculadas em hidrogéis para administração cutânea: desenvolvimento, caracterização e avaliação biológica in vitro e in vivo. 2019. 124f, Dissertação (mestrado), Universidade Estadual Paulista "Júlio de Mesquita Filho", Faculdade de Ciências Farmacêuticas, Araraquara, SP. 2019.

PITTELLA, C. Q. P. Desenvolvimento de scaffold de nanocelulose bacteriana com modificação de superfície para aplicações tópicas. 2017. 144 f. Tese (doutorado) - Universidade Federal de Santa Catarina, Centro Tecnológico, Programa de Pós-Graduação em Engenharia Química, Florianópolis. 2017. 
REZENDE, T. C. Preparação e caracterização de hidrogel com nanopartícula de cério, Calendula officinalis ou Bixa orellana L., como potenciais curativos de feridas crônicas. 2018. 78 f. Dissertação (mestrado) - Universidade Federal do Espírito Santo, Programa de Pós-Graduação em Engenharia Química, Alegre, ES. 2018.

RIBEIRO, F. C. Desenvolvimento de formulações probióticas para prevenção da candidose bucal: estudo in vitro e in vivo. 2019. 83f. Tese (doutorado) - Universidade Estadual Paulista, Instituto de Ciência e Tecnologia, São José dos Campos, SP. 2019.

RIBEIRO, L. A. Uso de gel tri composto, "TRIGEL" (titânio + PVA + ac. hialurônico) associado ou não com células-tronco, no reparo da lesão osteo cartilaginosa: modelo animal. 2018. 60p. Dissertação (mestrado) - Universidade de São Paulo - Instituto de Química. São Paulo, SP. 2018.

RIGON, C. Hidrogel de base nanotecnológica contendo silibinina com ação anti-inflamatória no modelo de óleo de cróton. 2018. 129f. Dissertação (mestrado) - Universidade Federal de Santa Maria, Centro de Ciência e Saúde, Santa Maria, RS. 2018.

ROSA, L. C. Engenharia tecidual: desenvolvimento de um novo scaffold injetável para a aplicação na área da saúde. 2017. 101 f. Dissertação (mestrado) - Universidade Católica de Pelotas, Programa de Pós-Graduação em saúde e comportamento, Pelotas, RS. 2017.

ROSA, P. Desenvolvimento e avaliação biológica de preparações nanoestruturadas de desonida para uso tópico. 2018.103 f. Tese (doutorado) - Universidade Federal de Santa Maria, Programa de Pós Graduação em Ciências Farmacêuticas. Santa Maria, RS. 2018.

SACOMANI, D. P. Influência do tempol na estabilidade de hidrogéis de ácido hialurônico sob stress oxidativo para aplicações em ortopedia regenerativa. 2019. 86 f. Dissertação (mestrado) Universidade Estadual de Campinas, Faculdade de Engenharia Química, Campinas, SP. 2019.

SANTOS, V. H. Avaliação das células tronco mesenquimais derivadas de membrana sinoval equina inseridas em microcápsulas de hidrogel de alginato. 2017. 85 f. Dissertação (mestrado) Universidade Estadual Paulista, Botucatu, SP. 2017. 
SILVA, R. C. B-Galactosidase encapsulada em hidrogéis de carragenana, pectina e carragenana/ pectina: Estudo comparativo e fatores que influenciam na estabilidade e liberação controlada. 2017. 81 f. Dissertação (mestrado) - Universidade Federal de Alfenas, Alfenas, Programa de Pós-Graduação em Química, Alfenas, MG. 2017.

SILVA, T. C. Síntese e avaliação térmica de géis de ácido hialurônico: uso em preenchimento facial e viscosuplementação. 2019. 83 f. Dissertação (mestrado) - Universidade Estadual Paulista “Júlio de Mesquita Filho”, Instituto de Química, Araraquara, SP. 2019.

SILVEIRA, J. C. C. Cimentos ósseos alfa-fosfato tricálcio e alfa fosfato tricálcio de dupla pega: desenvolvimento/caracterização para fins de liberação controlada de fármacos e vigilância sanitária. 2017. 144 f. Tese (doutorado) - Universidade Federal do Rio Grande do Sul, Escola de Engenharia, Porto Alegre, RS. 2017.

SOUSA, F. D. Desenvolvimento de hidrogéis e membranas com ação cicatrizante contendo lectinas vegetais em matriz de galactomanana. 2017. 89 f. Tese (doutorado) - Universidade Estadual do Ceará, ede Nordeste de Biotecnologia, Fortaleza, CE. 2017.

STUEBER, K.; TEIXEIRA, M. R. F. Redes de conhecimento na comunicação científica em âmbito formal: panorama via Biblioteca Brasileira de Teses e Dissertações (2008-2018). AtoZ: novas práticas em informação e conhecimento, v. 8, n. 2, p. 91-98, 2020.

VASCONCELOS, M. Silveira. Hidrogel cicatrizante a partir de hemiceluloses vegetais de Caesalpinea pulcherrima e proteínas laticíferas de Calotropis procera. 2017. 139 f. Tese (doutorado) - Universidade Federal do Ceará, Centro de Ciências, Fortaleza, CE. 2017.

VICENTINE, A. B. A utilização do hidrogel com papaína no tratamento de feridas em pés diabéticos. 2016. 107f. Dissertação (mestrado) - Instituto de Pesquisas Energéticas e Nucleares, São Paulo. SP. 2017.

WESTIN, C. B. Desenvolvimento de hidrogéis poliméricos termossensíveis contendo agentes bioativos para engenharia de tecido cartilaginoso. 2020. $141 \mathrm{f}$. Tese (doutorado) - Universidade Estadual de Campinas, Faculdade de Engenharia Química, Campinas, SP. 2020. 